\title{
The Effects of COVID-19 on the Mental Health of the Peruvian Police and Armed Forces
}

\author{
Tomás Caycho-Rodríguez ${ }^{1 \star}$, Miguel Barboza-Palomino ${ }^{1}$, Carlos Carbajal-León ${ }^{1}$, José Heredia-Mongrut ${ }^{2}$, \\ Miguel Gallegos ${ }^{3,4}$, Lindsey W. Vilca ${ }^{5}$, Viviane de Castro Pecanha ${ }^{6}$
}

\author{
${ }^{1}$ Facultad de Ciencias de la Salud, Universidad Privada del Norte, PERU \\ ${ }^{2}$ Unidad de Tutoría Universitaria, Facultad de Arquitectura y Urbanismo, Universidad Privada de Tacna, PERU \\ ${ }^{3}$ Facultad de Ciencias de la Salud, Universidad Católica del Maule, Talca, CHILE \\ ${ }^{4}$ Consejo Nacional de Investigaciones Científicas y Técnicas, ARGENTINA \\ ${ }^{5}$ Departamento de Psicología, Universidad Peruana Unión, PERU \\ ${ }^{6}$ International Psychology Department, The Chicago School of Professional Psychology (Online Campus), USA \\ *Corresponding Author: tomas.caycho@upn.pe
}

Citation: Caycho-Rodríguez T, Barboza-Palomino M, Carbajal-León C, Heredia-Mongrut J, Gallegos M, Vilca LW, de Castro Pecanha V. The Effects of COVID-19 on the Mental Health of the Peruvian Police and Armed Forces. Electron J Gen Med. 2021;18(3):em292. https://doi.org/10.29333/ejgm/10839

\section{ARTICLE INFO}

Received: 17 Oct. 2020

Accepted: 23 Feb. 2021

\begin{abstract}
The COVID-19 pandemic has had a profound impact on the mental health of the general population. However, little attention has been given to the mental health of a group considered an essential category, police officers and the members of the armed forces. This study examined the mental health of 204 members of the armed forces and the police department assigned to monitor the public roads to enforce the measures adopted by the Peruvian government. The instruments used in the study included the Fear of COVID-19 Scale (FCV-19S), and the Revised Mental Health Inventory-5. The results indicate that (during the last month), the majority of the participants felt nervous and edgy (81.8\%), and hopeless or sad (68.2\%). According to the participants, the feelings of hopelessness and discouragement were significantly affecting their ability to rebound (84.3\%). Participants had mixed feelings in regards of the fear generated by COVID-19, $42.6 \%$ reported extreme anxiety or panic, $40.6 \%$ were uncomfortable to think about COVID-19, and $42.6 \%$ were afraid of losing their lives due to the illness. The fear of COVID-19 predicted $19.7 \%$ (Adjusted $\mathrm{R}^{2}=0.197 ; \mathrm{F}=21.32 ; p=.000$ ) of the participants' mental health well-being. In summary, the results suggest the presence of important psychological stressors related to COVID-19 that could potentially led to the development of mental health disorders among the Peruvian police and armed forces.
\end{abstract}

Keywords: mental health, police, armed forces, Peru

Dear Editor,

The COVID-19 pandemic has had a profound impact on the mental health of the general population increasing feelings of loneliness and fear, and causing symptoms of anxiety, depression and stress [1]. Current studies have been examining the effects of COVID-19 among those diagnosed with the illness and their close family members and friends; individuals with pre-existing mental health disorders and their vulnerability to biological and psychosocial stressors; the risks posed by the overexposure to the news; and the hazards in the healthcare field [2]. Interestingly, little attention has been given to the mental health of a group considered an essential category, police officers and the members of the armed forces [3,4].

As already known, mental health problems are frequent among law enforcement personnel [5]. Nonetheless, such problems do not account for the additional level of stress affecting this population in times of COVID-19 pandemic [6]. High demand of work to keep the public safe, risk of COVID-19 infection, and scare resources are factors that also have consequences on the psychological wellbeing of individuals working in the law enforcement field - this is the current situation in Peru [3]. The official number of COVID-19 cases and deaths in this population has exceeded any other professional group in similar line of work (first respondents) in Peru and around the world [4]. Maintaining the mental wellbeing of Peruvian army and police officers became a public health concern requiring immediate attention.

This study examined the mental health of 204 members of the armed forces and the police department assigned to monitor the public roads to enforce the measures adopted by the Peruvian government. The vast majority of participants were men $(89.7 \%)$, single (59.3\%), and the average age was 29.28 years $(S D=11.29)$. The Peruvian Army accounted for $58.3 \%$ of the sample, followed by $31.4 \%$ from the Peruvian National Police, $7.8 \%$ from the Peruvian Air Force and 2.5\% from to the Peruvian Navy. All the participants reported having children even though $61.3 \%$ were not living with them. Most of the participants were not diagnosed with COVID-19 (85.8\%) although they reported having close or distant relatives $(86.8 \%)$, and colleagues (76\%) diagnosed with the disease.

The instruments used in the study included the Fear of COVID-19 Scale [7] (FCV-19S), and the Revised Mental Health Inventory-5 [8]. The results indicate that (during the last month), the majority of the participants felt nervous and edgy 
$(81.8 \%)$, and hopeless or sad (68.2\%). According to the participants, the feelings of hopelessness and discouragement were significantly affecting their ability to rebound (84.3\%). In general, studies focused in pandemic contexts report the presence of fear of infection, fear of infecting relatives, and the concern of family members to become ill [9].

Participants had mixed feelings in regards of the fear generated by COVID-19, $42.6 \%$ reported extreme anxiety or panic, $40.6 \%$ were uncomfortable to think about COVID-19, and $42.6 \%$ were afraid of losing their lives due to the illness. Contrastingly, only $52.9 \%$ of the participants did not feel nervous when watching news about COVID-19, and $17.1 \%$ reported feelings of anxiety (e.g., sweaty hands) when thinking about the disease. A relatively high number of participants indicated having insomnia (62.3\%). The fear of COVID-19 predicted 19.7\% (Adjusted $\mathrm{R}^{2}=0.197 ; \mathrm{F}=21.32 ; p=.000$ ) of the participants' mental health well-being. This finding is aligned with the recent scientific literature on COVID-19 confirming that the fear of becoming ill is the most significant factors responsible for prompting high levels of stress [7].

In summary, the results suggest the presence of important psychological stressors related to COVID-19 that could potentially led to the development of mental health disorders among the Peruvian police and armed forces. The early detection of such indicators is key to inform preventive interventions to address the psychological wellbeing of this population. The mental health of law enforcement personnel should not be neglected especially considering their work as first line respondents to the COVID-19 pandemic in Peru. Most certainly, this population could benefit from receiving immediate support to manage the emotional distress caused by COVID-19 pandemic. To that end, the following such be considered as guidelines to formulate specific public policies in order to prevent the development of mental health illness among Peruvian law enforcement personnel: (a) providing specialized mental health assistance for the staff and their families, (b) enhancing their psychosocial network support systems to include relaxation and desensitization activities (after the end of a working day), and (c) promoting good eating habits, personal hygiene, and developing basic healthcare skills to monitor one's own psychological wellbeing.

Author contributions: TC-R designed the study, performed the statistical analysis and wrote the article, MB-P, CC-L, JH-M, collected data and, MG critically reviewed and wrote the article, LWV performed the statistical analysis, VCP critically reviewed and wrote the article. All authors approved the final version of the manuscript

Funding: The study received no funding.

Declaration of interest: Authors declare no competing interests.

\section{REFERENCES}

1. Torales J, O'Higgins M, Castaldelli-Maia JM, Ventriglio A. The outbreak of COVID-19 coronavirus and its impact on global mental health. Int J Soc Psychiatry 2020;66(4):31720. https://doi.org/10.1177/0020764020915212 PMid: 32233719

2. Fiorillo A, Gorwood P. The consequences of the COVID-19 pandemic on mental health and implications for clinical practice. Eur Psychiatry 2020;63(1):e32. https://doi.org/ 10.1192/j.eurpsy.2020.35 PMid:32234102 PMCid: PMC7156565

3. Guo X, Wu L, Yu X, Sun Z, Liu W. Mental Health Care for Military Personnel in the COVID-19 Epidemic. Mil Med, 2020;185(9-10):e1401-5. https://doi.org/10.1093/mil med/usaa127 PMid:32559299 PMCid:PMC7337873

4. Hernández-Vásquez A, Azañedo D. COVID-19 in Peru: the need to pay attention to the high number of police deaths due to the pandemic. J Public Health 2020;42(3):640-1. https://doi.org/10.1093/pubmed/fdaa079 PMid:32529227 PMCid:PMC7313778

5. Syed S, Ashwick R, Schlosser M, Jones R, Rowe S, Billings J. Global prevalence and risk factors for mental health problems in police personnel: a systematic review and meta-analysis. Occup Environ Med. 2020;77:737-47. https://doi.org/10.1136/oemed-2020-106498 PMid:32439827

6. Stogner J, Miller BL, McLean K. Police stress, mental health, and resiliency during the COVID-19 pandemic. Am J Crim Justice 2020;45(4):718-30. https://doi.org/10.1007/s12103020-09548-y PMid:32837167 PMCid:PMC7319488

7. Ahorsu DK, Lin CY, Imani V, Saffari M, Griffiths MD, Pakpour $\mathrm{AH}$. The fear of COVID-19 scale: development and initial validation. Int J Ment Health Addiction 2020; 1-9. https://doi.org/10.1007/s11469-020-00270-8

8. Rivera-Riquelme M, Piqueras JA, Cuijpers P. The Revised Mental Health Inventory-5 (MHI-5) as an ultra-brief screening measure of bidimensional mental health in children and adolescents. Psychiatry Res 2019;274:247-53. https://doi.org/10.1016/j.psychres.2019.02.045 PMid:30818147

9. Souadka A, Essangri H, Benkabbou A, Amrani L, Majbar MA. COVID-19 and Healthcare worker's families: behind the scenes of frontline response. EClinicalMedicine, 2020;23: 100373. https://doi.org/10.1016/j.eclinm.2020.100373 PMid:32368726 PMCid:PMC7196421 